Tropical Journal of Pharmaceutical Research September 2015; 14 (9): 1695-1701

ISSN: 1596-5996 (print); 1596-9827 (electronic)

(C) Pharmacotherapy Group, Faculty of Pharmacy, University of Benin, Benin City, 300001 Nigeria.

All rights reserved.

Available online at http://www.tjpr.org

Original Research Article

http://dx.doi.org/10.4314/tjpr.v14i9.22

\title{
Psychological Impact of Life as Refugees: A Pilot Study on a Syrian Camp in Jordan
}

\author{
Basheti IA, Qunaibi EA and Malas R \\ Applied Sciences University, PO Box 940344, Amman, 11194, Jordan
}

${ }^{*}$ For correspondence: Email: dr_iman@asu.edu.jo; Tel: +962-799048003; Fax: +9626-5515017

Received: 1 July 2014

Revised accepted: 29 June 2015

\begin{abstract}
Purpose: To investigate types and prevalence of psychological distresses endured by Syrian refugees at Alzatary Camp in Jordan.

Methods: This observational study was conducted over a period of 2 months (November and December, 2012) at Alzatary Camp for Syrian refugees in Jordan. A validated questionnaire was filled by a field researcher to gather information on respondents' living conditions, psychological distresses and perspectives of the medical care services provided.

Results: The questionnaire was completed for 73 respondents with a mean age of $37.7 \pm 11.2$. A majority of refugees (63.3\%) lived in tents, and the rest in caravans. Some of the respondents (56\%) suffered from psychological distresses; $46 \%$ believed that psychological therapy and support is needed, out of which $14.5 \%$ reported receiving such therapy. Refugees staying in tents reported low satisfaction with the medical care services provided (54.2 \% vs. $23.8 \%$ ) and great need for psychological support (66.7\% vs. $31.3 \%$ ) when compared to refugees staying in caravans.

Conclusion: Syrian refugees at Alzatary Camp suffer from psychological distress that requires urgent attention. Current medical support is not sufficient, especially for refugees staying in tents.
\end{abstract}

Keywords: Syrian refugees, Jordan camps, Alzatary Camp, Psychological disorders, Mental health

Tropical Journal of Pharmaceutical Research is indexed by Science Citation Index (SciSearch), Scopus, International Pharmaceutical Abstract, Chemical Abstracts, Embase, Index Copernicus, EBSCO, African Index Medicus, JournalSeek, Journal Citation Reports/Science Edition, Directory of Open Access Journals (DOAJ), African Journal Online, Bioline International, Open-J-Gate and Pharmacy Abstracts

\section{INTRODUCTION}

Since the Syrian conflict began over two years ago, many Syrian refugees fled the war zones to Jordan. To host most of these refugees, several camps were opened by the Jordanian government. Alzatary Camp, first opened in 28 July 2012 is considered the biggest and is estimated to be housing 30,000 Syrian refugees as of 6 September 2012, comprising about $30 \%$ of the total Syrian refugees in Jordan [1].

Medical care has been provided to the Camp by international field hospitals, such as the Moroccan, Italian, and French, in addition to the
United Arab Emirates and Jordanian Red Crescent. Yet, the situation in the Camp is not satisfactory in many ways, and there have been reports that the Camp is not very well-equipped, particularly for providing needed health care services $[2,3]$.

Refugees forced out of their countries, exposed to events before, during and after migration suffer psychological distresses that influence their mental health to a great extent [4-7]. High prevalence of mental illnesses in refugees has been reported in numerous previous studies $[8,9]$. Worse outcomes have been reported for refugees living in institutional accommodation 
and experiencing restricted economic opportunities [4]. Hence, health care services should target refugees' psychological distresses by initiating contact with them from arrival in the receiving country [9]. In light of all this, a study looking into the current psychological health distresses of the Syrian refugees in Jordan is promptly warranted. The aim of this study is to investigate the current psychological distresses suffered by Syrian refugees at Alzatary Camp in Jordan and to assess their perspectives of the health care services provided to them.

\section{METHODS}

\section{Study setting}

The study was conducted in 2012 at Alzatary Camp for the Syrian refugees in Jordan. Ethics approval was obtained from the Faculty of Pharmacy, Applied Sciences University. The study was carried within a period of 2 months (November and December).

\section{Study design}

This observational study was conducted with a questionnaire prepared by the research team. The questionnaire was made up of questions that have been previously identified as 'essential' when assessing the adequacy and effectiveness of health care service delivery in conflict affected areas $[10,11]$. It had three different parts of closed and open-ended type of questionnaire. Part A investigated participants' demographic information (age, gender, marital status, number and gender of family members for each participant, shelter type, and period spent at the Camp). Part B investigated the respondents' medical status (chronic and/or acute illnesses they suffered in the previous month), perspectives of the medical services they were receiving, presence of a special case in the family such as pregnancy, physical and/or mental disability, death while living at the Camp and causes of death if any. Part $C$ consisted of questions assessing psychological distresses suffered by the patients, their perceived need for psychological treatment and whether any such treatment was offered to them at the Camp.

To ensure face validity, the questionnaire was evaluated by academics possessing previous experience in clinical studies. The questionnaire was then pretested by pharmacy students ( $\mathrm{n}=$ 10) and validated for clarity of questions. Views and comments of the students were considered by the researchers and then incorporated where appropriate into the final versions of the questionnaire. To assess test-retest reliability, the questionnaire was administered on two occasions to 15 randomly selected pharmacy students. The second testing took place two weeks after the first one. Test retest reliability was calculated using Spearman's correlation coefficient $(r)$, which was 0.90 in this study, implying acceptable test-retest reliability.

Survey random sampling was used, where the researcher approached people living in randomly selected tents/caravans at the Camp. The person that responded to the researcher from each tent/cabinet was offered to participate in the study, and an information leaflet was provided upon acceptance. Verbal consent was sought from the respondent before the survey was completed. The number of people that declined from participating in the study was reported to account for the amounts of non-response.

\section{Outcomes measured}

The main outcome measure in this study was to investigate psychological distresses suffered by the respondents. The instrument used Likert scale to measure the level of agreement, ranging from ' 1 ' equalling 'never' to '4' equalling 'always'. The items of this instrument were derived from previously published research [11]. The questions investigated whether participants have had specific feelings or have acted in a certain way within the past month. These feelings involved becoming angry easily, feeling fearful, feeling nervousness or shakiness inside, having difficulty falling asleep or staying asleep, feeling hopeless about the future, or having spells of terror or panic.

Second outcome measures include determining associations between certain factors and respondents' beliefs whether they were provided with proper medical care at the Camp and whether psychological treatment was needed. These factors included type of shelter; period spent in Camp; gender; marital status; number of family members; answer to the question "Do you or any of your family members suffer from any illnesses (yes, no)"; answer to the question "Do you have a special case in your family (yes, no)".

\section{Data collection}

A researcher approached the refugees living in the Camp randomly. Respondents who agreed to take part in the study (answer the questionnaire) provided informed oral consents. Completed questionnaires were inserted in envelops at the end of the interview by the field researcher and returned for data entry and analysis. 
The field researcher (pharmacist) introduced herself as an independent figure and not a health care professional or a person that can make decisions or changes. This was a process measures to overcome cognitive bias that can lead to respondents answering questions not completely according to their true beliefs.

\section{Data analysis}

Participants' responses were encoded and the data were analyzed using Statistical Package for the Social Sciences (SPSS, version 17, Chicago, IL, US). Descriptive analysis was carried out to determine proportions for categorical data. Chi square test was used to identify correlations and significant differences amongst participants' responses, with significance defined as $p \leq 0.05$. In order to determine predictors (shown under outcome variables) of respondents' beliefs whether they were provided with proper medical care at the Camp and whether psychological treatment and support was needed, a logistic linear regression analysis was performed (Table 1).

\section{RESULTS}

During the 8 weeks of study, 73 respondents completed the questionnaire, in a mean time of $25.3 \pm 10.3 \mathrm{~min}$. Mean age of respondents was $37.7 \pm 11.2$ (age range $=19$ to 60 years), $60.8 \%$ were males, and most of them (94.2\%) were married.
A majority of the respondents $(76.1 \%)$ reported living at the Camp for a period exceeding the 1 month. Majority $(63.3 \%)$ were living in tents, and the rest in caravans. Mean number of family members reported by the respondents was $7.0 \pm$ 3.3 (mean $\pm \mathrm{SD}$ ), with about equal numbers of males $(3.6 \pm 2.0)$ and females $(3.3 \pm 2.1)$.

Presence of illnesses amongst the participants was reported by $79.5 \%$ of them. These illnesses and their frequencies are shown in Figure 1. From the afflicted refugees who reported their type of illnesses $(67.1 \%)$, about half of them $(55.1 \%)$ had acute illnesses, $16.3 \%$ had chronic illnesses, and the rest $(28.6 \%)$ a combination between the two.

Special medical cases amongst the family members of the respondents were reported by $38.4 \%$ of them. Pregnancy accounted for $71.4 \%$ of these cases, $17.7 \%$ involved physical disabilities, while $10.4 \%$ involved central nervous system disorders.

Three respondents $(4.1 \%)$ reported death of a family member during their stay at the Camp, due to timely lack of medical attention. The deaths were due to an asthma attack, hyperthermia and food poisoning.

Forty three percent of respondents agreed/strongly agreed that a proper medical care was provided for them and their family members. Some $(19.0 \%)$ were not sure, while the rest $(38.0 \%)$ disagreed/strongly disagreed.

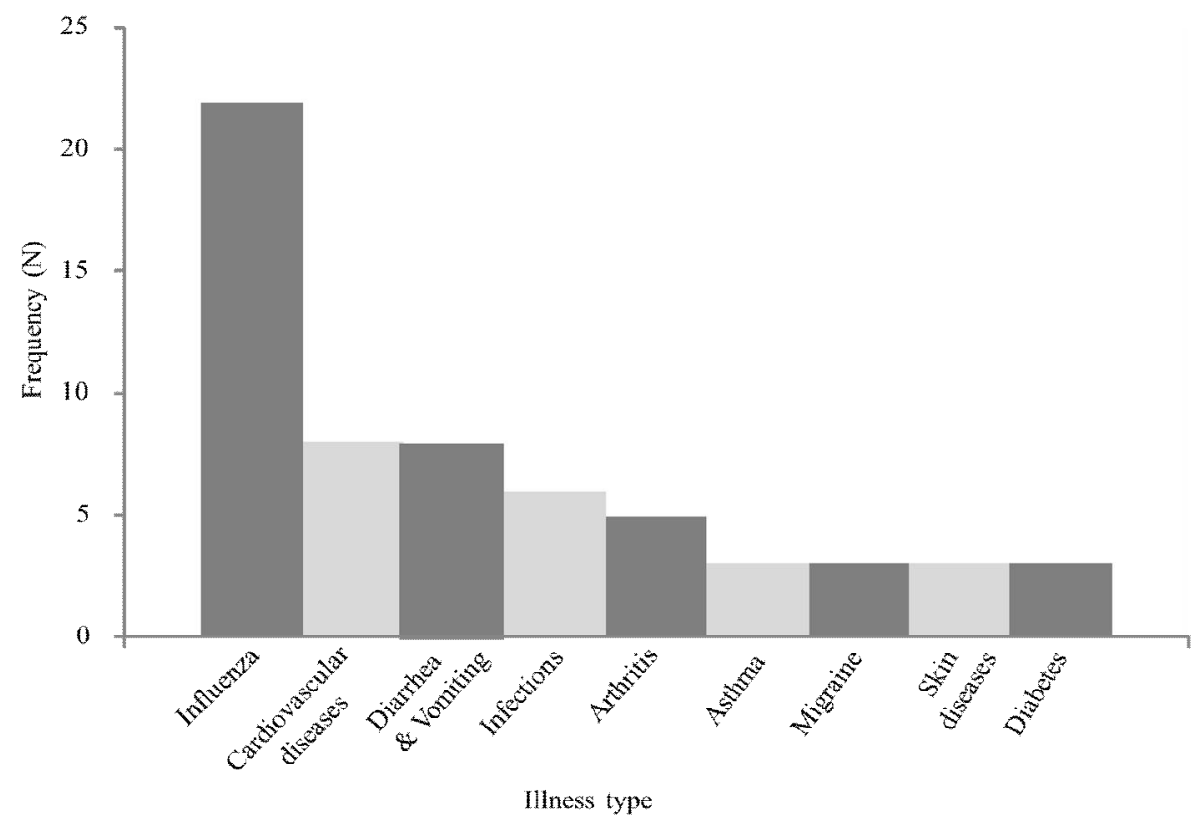

Figure 1: Frequency of the illnesses (acute and chronic) afflicted by the refugees $(n=73)$ at Alzatary Camp 
A significant association between the number of respondents who reported suffering from illnesses, and dissatisfaction with the medical care provided at the Camp was found ( $p=0.020$, Chi square t test). Many respondents (26.0\%) reported dissatisfaction with the availability of medications needed for the treatment of their (or their family members) medical conditions (Figure 2).

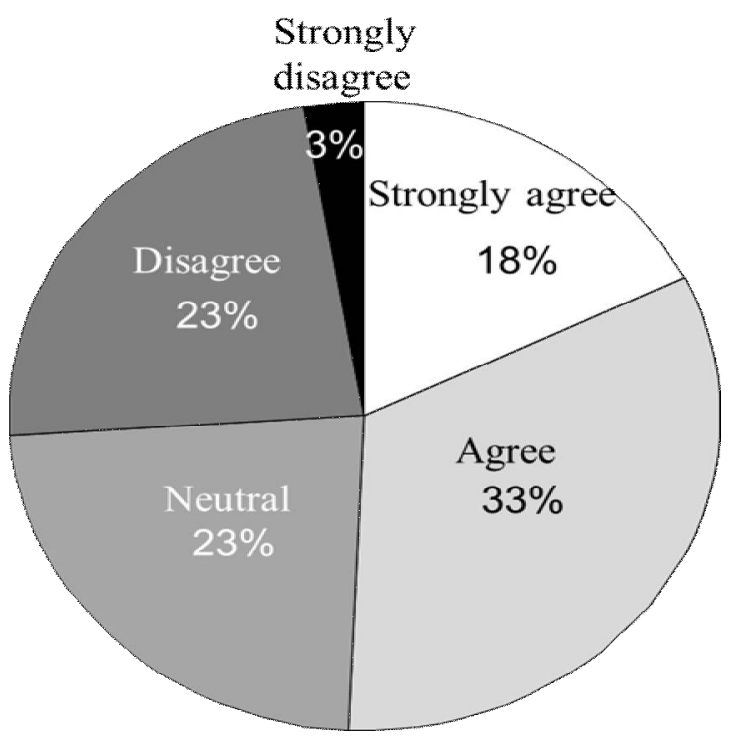

Figure 2: Perspectives of the refugees $(n=73$ ) regarding the availability of needed medications at the Alzatary Camp. Refugees chose between 'strongly agree', 'agree', 'neutral', 'disagree', or 'strongly disagree'

The final resultant model $\left(R^{2}=0.238, p=0.042\right)$ from the logistic analysis reporting on the dependent variable, "respondents perspective regarding the medical care provided at the Camp", showed significant association with the type of shelter the participants were living in $(p=$ $0.03)$, and presence of illnesses $(p=0.016)$. Refugees who were staying in caravans reported significantly higher satisfaction with the medical care provided at the Camp than refugees staying in tents (Table 1, Model A).

Psychological assessment showed a high proportion of respondents (56\%) suffering from one or more of the following: anger, fearfulness, nervousness, difficulty falling asleep or staying asleep, hopelessness about the future and spells of terror and panic (Figure 3). Some of the respondents refused to answer to some of these distresses. About one third of the respondents $(37.3 \%)$ suffered all six distresses.

While $54 \%$ of respondents reported that psychological treatment and support is not needed, $46 \%$ reported the need for such support. Out of the participants (46\%) who reported their need for psychological support and treatment, $14.5 \%$ stated receiving such treatment at the Camp.

State of living at the Camp made a significant difference to the reported need of psychological support. A significantly higher proportion of refugees staying in tents reported the need for psychological support when compared to refugees staying in caravans (Table 1 , Model B).

Table 1: Summary of the regression models for the dependent variables $A$ and $B$, with its associated predictors, size and direction of the association $(n=73)$

\begin{tabular}{|c|c|c|c|c|c|c|}
\hline \multirow{2}{*}{$\begin{array}{l}\text { Variable } \\
\text { Associated predictor }\end{array}$} & \multicolumn{3}{|c|}{$\begin{array}{l}\text { Model A } \\
\text { “Refugees believe that they are } \\
\text { receiving the proper medical } \\
\text { care at the Camp” }\end{array}$} & \multicolumn{3}{|c|}{$\begin{array}{l}\text { Model B } \\
\text { "Refugees believe that } \\
\text { psychological support and } \\
\text { treatment is needed" }\end{array}$} \\
\hline & Beta & $t$ & P-value & Beta & $t$ & P-value \\
\hline Type of shelter & 0.411 & 2.264 & 0.030 & -0.436 & -2.428 & 0.020 \\
\hline Period spend in Camp & 0.017 & 0.096 & 0.924 & -0.098 & -0.565 & 0.576 \\
\hline Gender & -0.183 & -1.094 & 0.281 & -0.089 & -0.539 & 0.593 \\
\hline Marital status & -0.061 & -0.398 & 0.693 & -0.077 & -0.506 & 0.616 \\
\hline Number of family members & -0.226 & -1.412 & 0.167 & 0.207 & 1.312 & 0.198 \\
\hline $\begin{array}{l}\text { Presence of illnesses } \\
\text { amongst family members }\end{array}$ & -0.393 & -2.539 & 0.016 & 0.030 & 0.194 & 0.847 \\
\hline $\begin{array}{l}\text { Presence of a special case } \\
\text { amongst family members }\end{array}$ & -0.078 & -0.512 & 0.612 & 0.035 & 0.234 & 0.816 \\
\hline
\end{tabular}

"Beta" is the standardized regression coefficient, "Beta" values with their " $p$ " values show whether each variable is making a statistically unique contribution to the model $(p<0.05)$ or not. The t test given by the " $T$ " value, tests the significance of each coefficient, it can determine the relative importance of each variable in the model (useful predictors usually have "t" values above 2 or below -2) 


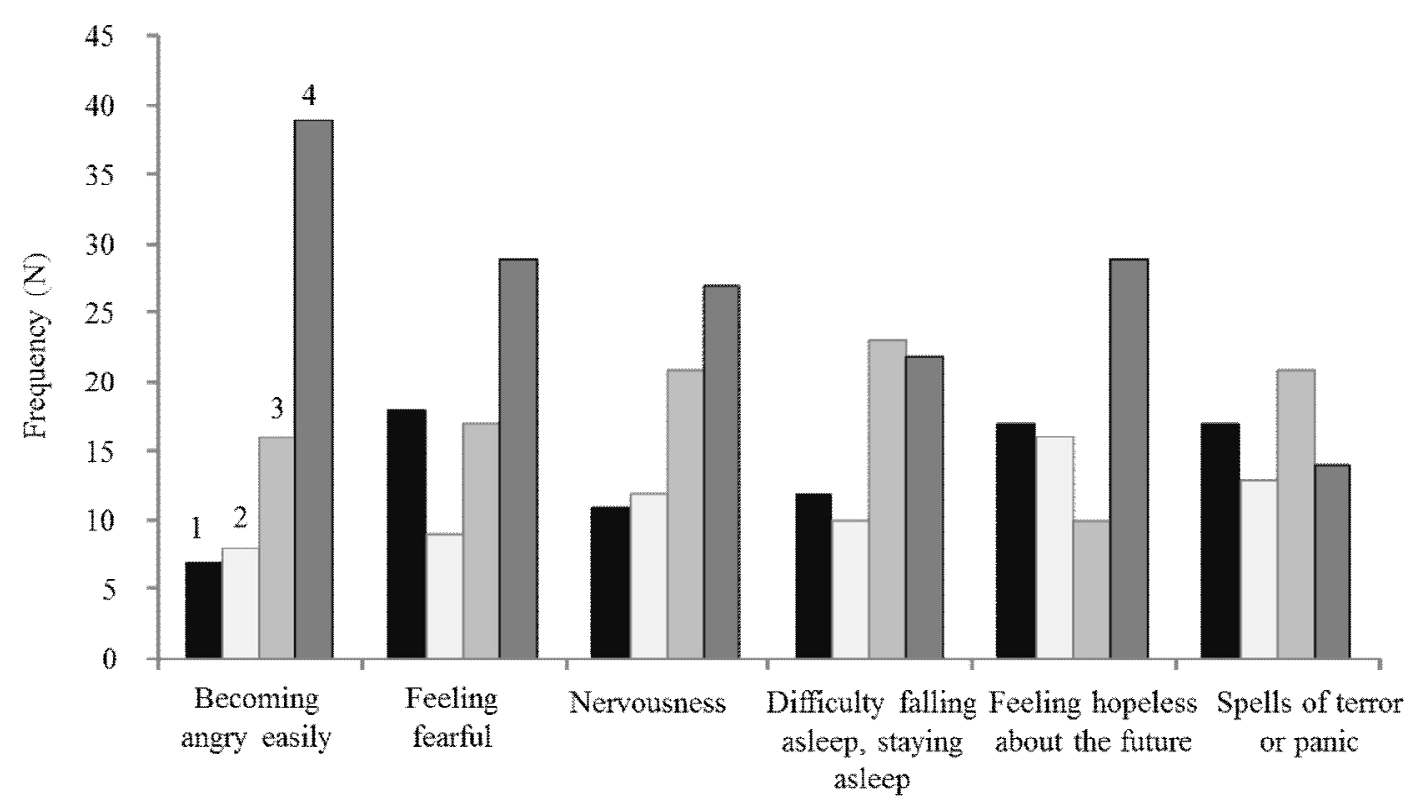

Psychological distresses reported by refugees

Figure 3: Proportion of experienced psychological distresses reported by the refugees $(n=73)$ during their stay at Alzatary Camp during the past month. For each type of psychological distress, participants had to choose between: never (1), sometimes (2), often (3), and always (4)

This was revealed through the results of the logistic analysis modeling the dependent variable, "Do you believe that psychological support/treatment is needed" $\left(R^{2}=0.255, p=\right.$ $0.004)$ showing a significant association with the type of shelter $(p=0.020)$.

\section{DISCUSSION}

Several reports have mentioned that Syrian refugees staying at the Alzatary Camp in Jordan have been provided with services of security, food, health care, and education [2,3]. However, this study is the first to shed light on the medical care services provided in Jordan through the eyes of the Syrian refugees. This study also unveils important issues regarding refugees' psychological distresses and needs. Refugees' perspectives of the medical care services provided at the Camp exposed dissatisfaction, which could be augmenting the psychological distresses reported [4].The psychological care at the Camp requires development, calling upon the health care service providers at the Camp.

Flu, diarrhea, infections and cardiovascular problems were the health problems refugees at the Camp mostly suffered from. The high proportion of chronic medical conditions amongst the refugees did not present a predicament, presumably they were triggered prior to Camp settlement. What was surprising is the high proportion of refugees $(53.1 \%)$ reporting the presence of acute illnesses, introduced during their stay at the Camp. Infection control and outbreak surveillance programs need to be implemented at the Camp, monitoring specific clinical indicators, to assure the quality of the provided prophylactic services and decrease the rate of acquired acute illnesses.

Results of this study regarding the effectiveness of the medical care services provided at the Alzatary Camp have revealed variations in the perceived satisfaction amongst the refugees. Dissatisfaction was reported by $38 \%$, while $43 \%$ were satisfied. Unavailability of needed medications was a problem reported by about half of the refugees, while the other half reported contentment. Significant association between the type of shelter and satisfaction of refugees with the medical care they were receiving was found, with refugees staying in caravans showing greater satisfaction when compared to those who were staying in tents. These findings indicate differences in the standard of care delivered to the refugees at the Camp. The situation needs to be reevaluated, especially when considering the remarkable increase in the number of refugees on monthly basis, and a dedicated medical/paramedical team is needed to coordinate and asses the needs, both current and emerging. 
In the time of conflicts, psychological problems surpass, and if left unattended, can lead to unfortunate outcomes [14]. Psychological assessment and treatment were requested by half of the participants only, which is not surprising considering that most of them have never received such care and hence are unaware of its necessity [15]. The short questionnaire designed for this study was set to take a maximum of $15 \mathrm{~min}$, yet it took more than half an hour for the researcher to complete it for each of the respondents. The respondents were eager to talk and share their own stories with the researcher, longing for a chat that may sooth their nerves and calm their tension down. Being a survivor of war and possible torture, talking and sharing stories is not expected to happen on the refugees own initiative, so approaching the refugees is vital [17]. This approach may involve helping the refugee to tell the story of what happened to them until it no longer elicits anxiety, a treatment technique known as narrative exposure therapy, commonly used to treat the effects of trauma in refugees and to prevent psychiatric illness [18].

A high proportion of refugees at Alzatary Camp reported suffering from anger, fearfulness and nervousness. Considering the current situation at the Camp, and the war situation that the refugees had to go through before arriving, these results were not surprising. Post-traumatic stress disorder and its concomitant psychosocial problems in similar nearby war events have been previously documents [16].

A previous study conducted in Turkey investigating the current situation for the Syrian refugees there [15] designated lack of knowledge by authorities regarding psychological problems in harsh situations as an important issue that ought to be addressed. Language barriers and cultural differences were recognized as obstacles to addressing psychological problems in Turkey [15]. In Jordan, people speak the same language as the Syrian refugees, and have little cultural differences, making it more feasible to attend to the psychological distresses suffered by the refugees at the Alzatary Camp.

Psychological treatment can prevent dangerous consequences at the Alzatary Camp, such as escalations, violence, and rise of mental conditions such as anxiety, depression and suicide $[8,9,20]$. This strongly indicates the need for a specialized team of psychiatrists and counselors, along with a training mental program aimed at reviewing cases in need of special psychiatric evaluation and treatment.
It is interesting to note that refugees staying in tents reported a higher need for psychological support than those staying in caravans. This relationship between the shelter type and the different psychological needs at the Camp warrants further attention and investigational studies. It has been demonstrated that living conditions and insecurity are important factors showing strong association with general psychological health status [19].

\section{Limitations of the study}

One limitation of this study is that the results regarding the respondents reporting psychological distresses at the Camp do not really reflect whether these problems emerged during their stay at the Camp or were developed at some stages prior to their Camp settlement. Nevertheless, the reality that these psychological issues exist at the Alzatary Camp answers the main aim of the study and calls for the development and implementation of programs targeted at increasing health awareness and addressing the psychological issues being experienced by the refugees.

\section{CONCLUSION}

Syrian refugees at Alzatary Camp suffer from numerous psychological distresses that require urgent attention by the responsible authorities. About half of the refugees reported dissatisfaction with the care provided to them and to their family members at the Camp. Refugees staying in tents reported greater dissatisfaction compared to refugees staying in caravans. Results of this study necessitate the establishment of a dedicated medical team to assess and coordinate the care delivered by the different international field hospitals available at the Camp, with a special focus on the refugees' mental health.

\section{REFERENCES}

1. Rudoren J. Market rises, perfume and all, as refugees face a long syria war New York Times, 2012 [Cited 2013 Feb 21]. Available from http://www.nytimes. com/2012/11/01/world/middleeast/market-rises-atzaatari-camp-for-syrian-refugees.html.

2. World Health Organisation. Refugees in crisis, 2013 [cited 2013 Feb 1]. Available from: http://www.emro. who.int/jor/jordan-infocus/refugees-in-crisis.html.

3. De Sojo M. WFP response to the Syrian refugee crisis 2013 [cited 2013 Feb 5]. Available from: http://www.wfp.org/stories/wfp-responds-syrianrefugee-crisis 
4. Porter M, Haslam N. Predisplacement and postdisplacement factors associated with mental health of refugees and internally displaced persons: a meta-analysis. Jama 2005; 294(5): 602-612.

5. Schweitzer R, Melville F, Steel Z, Lacherez P. Trauma, post-migration living difficulties, and social support as predictors of psychological adjustment in resettled Sudanese refugees. Aust N Z J Psychiatry 2006; 40(2): 179-187.

6. Laban CJ, Gernaat HB, Komproe IH, van der Tweel I, De Jong JT. Postmigration living problems and common psychiatric disorders in Iraqi asylum seekers in the Netherlands. J Nerv Ment Dis 2005; 193(12): 825832.

7. Jones $D$, Gill PS. Refugees and primary care: tackling the inequalities. BMJ 1998; 317(7170): 1444-1446.

8. Fazel M, Wheeler J, Danesh J. Prevalence of serious mental disorder in 7000 refugees resettled in western countries: a systematic review. Lancet 2005; 365(9467): 1309-1314.

9. Norredam M, Garcia-Lopez A, Keiding N, Krasnik A. Risk of mental disorders in refugees and native Danes: a register-based retrospective cohort study. Soc Psychiatry Psychiatr Epidemiol 2009; 44(12): 1023 1029.

10. The UN refugee Agency. Handbook of Emergencies, Available at: http://reliefweb.int/node/23398, Geneva: United Nations Higher Commissioner for Refugees. 2007. pp 1-582.

11. Bean M. Assessing the psychological distress and mental healthcare needs of unaccompanied refugee minors in the Netherlands [dissertation]. [Netherlands]: Faculty of Social and Behavioural Sciences, Leiden University; 2006.

12. World Health Organisation. Syrian Arab Republic, Jordan, Lebanon, Iraq 2012 [cited 2013 Feb 1].
Available from: http://www.emro.who.int/images/ stories/eha/documents/WHO_Syria_sitrep7_1012201 2.pdf.

13. Jordan Times online. Syria refugees fear long stay as French aid reaches Jordan, 2012 [Accesed on 2013 Feb 3]. Available from: http://jordantimes.com/syriarefugees-fear-long-stay-as-french-aid-reaches-jordan.

14. Steel Z, Chey T, Silove D, Marnane C, Bryant RA, van Ommeren M. Association of torture and other potentially traumatic events with mental health outcomes among populations exposed to mass conflict and displacement: a systematic review and meta-analysis. Jama. 2009; 302(5): 537-549.

15. Sahlool Z, Sankri-Tarbichi AG, Kherallah M. Evaluation report of health care services at the Syrian refugee camps in Turkey. Avicenna J Med. 2012; 2(2): 25-28.

16. Levy BS, Sidel VW. Adverse health consequences of the Iraq War. Lancet 2013; 381(9870): 949-958.

17. Burnett A, Peel M. Asylum seekers and refugees in Britain. The health of survivors of torture and organised violence. BMJ 2001; 322(7286): 606-609.

18. Gwozdziewycz N, Mehl-Madrona L. Meta-analysis of the use of narrative exposure therapy for the effects of trauma among refugee populations. Perm J. 2013; 17(1): 70-76.

19. Roberts B, Browne J. A systematic review of factors influencing the psychological health of conflictaffected populations in low- and middle-income countries. Glob Public Health; 6(8): 814-829.

20. Ferrada-Noli M, Asberg M, Ormstad K. Suicidal behavior after severe trauma. Part 2: The association between methods of torture and of suicidal ideation in posttraumatic stress disorder. J Trauma Stress 1998; 11(1): 113-124. 